\title{
The nature of sound and the sound of Nature
}

\author{
Philip Samartzis ${ }^{1}$
}

\section{Abstract}

This paper considers ways in which audio recording can be used to offer new ways of experiencing natural environments, through a series of interviews with leading sound artists who have worked in extreme and remote locations. Its aims are to discover why sound artists are increasingly being attracted to dangerous and volatile environments, and what it is that they discover about themselves and their surroundings once they are there. It uses interviews which provide insights into each artist's motives and observations, how they have been marked by their experiences and how these experiences have subsequently influenced the work that they produce. It discusses the effects of undertaking fieldwork in remote locations including the Galapagos Islands, Antarctica, Iceland, the Amazon and the Arctic, and the strategies that each artist used to adapt to the prevailing conditions. It also examines the different concepts and methods informing location field recording and the differences between notions of authentic documentation and constructed composition. As remote locations become increasingly accessible and the popularity of field recording gains traction, it is worth asking whether the artefacts produced are in themselves unique and valuable, or whether it is the personal preoccupations, memories and perceptions of the artist articulated through their recordings that are of most value when listening to these works.

\section{Introduction}

We think in terms of nature as being slow. But you're missing it all the time. It's very very fast.

(Eastley 2006, p. 45)

\footnotetext{
1 Dr Philip Samartzis, School of Art, RMIT University, GPO Box 2476, Melbourne, VIC 3001, philip.samartzis@rmit.edu.au. This chapter is adapted and enlarged from an essay titled 'Sound artists in extremis' that appeared in Art Monthly Australia in November 2009.
} 
Anyone who has taken an interest in the practice of field recording has probably noticed the extremes that artists have gone to in recent years to document difficult and remote locations. Some significant works to emerge from this burgeoning trend include Antarctica (1998) by Douglas Quin, ${ }^{2}$ Baikal Ice (2003) by Peter Cusack, ${ }^{3}$ recorded at Lake Baikal in Siberia, Arctic (2007) by Max Eastley, ${ }^{4}$ and Wind [Patagonia] (2007) by Francisco Lopez. ${ }^{5}$ Works such as these provide an insight into remote and inhospitable environments that are usually inaccessible to the rest of us. The recordings are often evocative, atmospheric and strange, as faraway environments are probed for specific signifiers that mark them with a highly unusual sonic and spatial imprint.

As someone who has enjoyed the work of these and many other sound artists investigating similar concepts, I asked myself about the logistical and philosophical underpinnings of this often hazardous art practice. What is it about these types of locations that makes them so attractive, and what are the challenges that have to be overcome in order to operate there?

On one hand I am curious about the physical and psychological demands that must be met in adapting to environments that can range from oppressively hot and humid to extremely cold and dry, not to mention the technical challenges that must be overcome to produce a useful artefact. On the other hand I wonder how truly distinctive some of these remote environments are, compared with ones that are much more common and readily available. For instance, how do we differentiate common atmospheric conditions such as precipitation and wind to arrive at a specific reading of a place as being different to another? How effectively does field recording capture the spaces and resonances of a particular location to arrive at a unique experience, or does the experience hinge on a conceptual premise to remove any perceived ambiguity embedded in the recording?

While field recording provides the listener with a sense of place, theorist Rick Altman $^{6}$ suggests that the concept of 'faithful documentation' or rendition occludes the more complex relationship between techniques of sound recording and aesthetic and, relatedly, social and political concerns. As listening itself involves a highly subjective psychoacoustic process, it is arguable that any audible event can be accurately rendered, yet the relationship between technique, technology, and aesthetics provides a much more sophisticated way to engage with the environment than ideas around 'faithful documentation'

2 Douglas Quin (1998) Antarctica CD. Miramar Recordings, Seattle.

Peter Cusack (2003) Baikal Ice (Spring 2003), CD. RER Megacorp, Surrey.

Max Eastley (2007) Arctic, CD. Cape Farewell, London.

Francisco Lopez (2007) Wind [Patagonia], CD. And/OAR, Seattle.

6 Rick Altman (1985) The technology of the voice: Part I. IRIS 3(1): 3-20; (1986) The technology of the voice: Part II. IRIS 4(1): 107-19. 
would suggest. In order to unpack these complex issues I asked some of the leading practitioners of location field recording to share their experiences, to reveal the rationale behind their practice and what they discovered about themselves when confronted with an inhospitable landscape.

\section{Inside the circle of fire}

English sound recordist Chris Watson is undoubtedly one the primary reasons that field recording has become such a popular activity among sound artists in the last 15 years. Because of the innovative amalgam of concepts and techniques informing his work, the CDs that he has published through UK label Touch provide a major reference for many working in the field (e.g. Watson 2003). Although Watson is clearly focused on the pure documentation of the natural environment, his work is often dynamic and complex, with a great sense of drama present regardless of whether it is a recording of wind, the African savannah or an Arctic iceshelf breaking. ${ }^{7}$ I asked Watson what was the most difficult natural environment he has had to work in, and what impediments had to be overcome. He replied:

I find this a difficult question as many environments are challenging in different ways. Deserts of varying types are some of the most difficult whether these are hot, dry and sandy or frozen glacial plains at the polar regions. However if I have to choose one particular location it would be Isla Santiago in the Galapagos Archipelago. This is a volcanic island formed entirely by swirls of black lava with no vegetation, no shade and no freshwater. I knew from experience what conditions were like on the island, so was prepared with water, sunscreen, a groundsheet to shelter under, recording equipment and food for the one day I was there. A small boat dropped me off just after sunrise and left me there until 1700h when I was collected. The island is uninhabited and I was there on my own. Midday temperatures were around 50 degrees Celsius in the middle of the island, cooler on the coast. The location was certainly unique and consequently had its own particular and special atmosphere. ${ }^{8}$

7 Watson, Chris (2003) Weather Report, CD. Touch, London.

8 C Watson, pers. comm., 8 May 2009. 


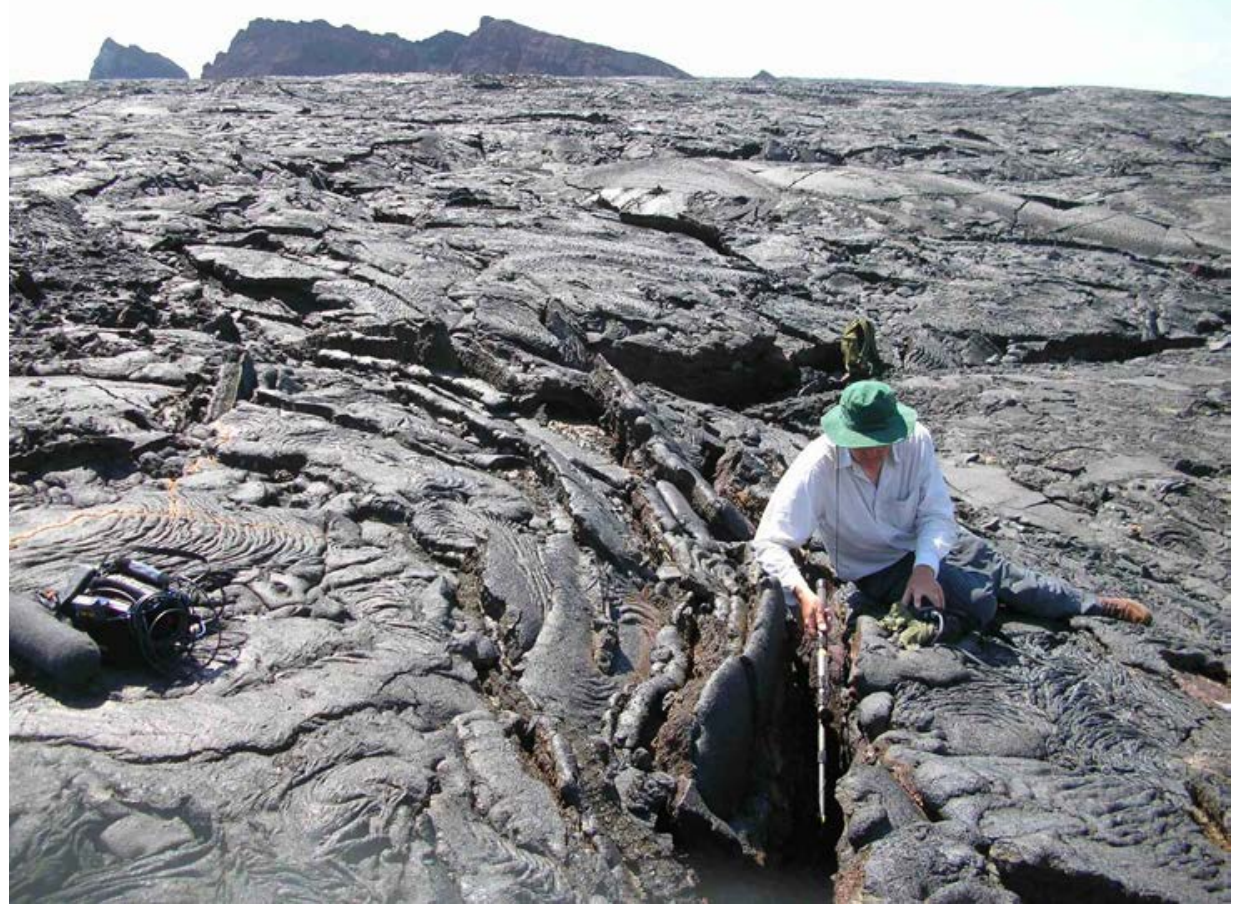

Figure 1. Chris Watson on Isla Santiago in the Galapagos Islands.

Source: Image courtesy of the artist.

Atmosphere is an indefinable quality that marks each and every location with a particular aural presence derived from the interplay of acoustics, sound and space. Additional factors such as temperature, humidity, vegetation, and geology contribute to the way sound propagates and the attendant psychoacoustic effects that emerge to define the aural experience. In a common outdoor environment such as a park, these types of interactions produce a familiar ambience often comprised of birdsong, insects, wind and water. However, there are other types of locations whereby a unique set of aural attributes coalesce to provide a more conspicuous atmosphere. What then is it about Isla Santiago that makes it different to other islands of the Galapagos?

The most westerly islands out in the Galapagos are the youngest, having most recently, in geological terms, emerged from the floor of the Pacific Ocean. Isla Santiago has no vegetation because it has yet to acquire any soil. Its bare volcanic rock is simply a template upon which a future island will emerge. At midday, with no wind, and away from the coastline, the sense and sound of quietness is breathtaking, and it seems difficult to break this ambience by creating any sound. Inland, and inside one of the strange lava tubes that I discovered, I managed to 
record one of the quietest animal sounds I have ever heard, the faint yet determined progress of a hermit crab as it scratched its way along the floor of this natural pipeline. ${ }^{9}$

\section{Faster than cold}

Douglas Quin is a US-based sound recordist who has travelled widely documenting the natural soundscape - from Antarctic ice to Arctic tundra and from African savannah to Amazon rainforest. Quin's recordings of endangered and disappearing habitats represent one of the most distinctive and extensive collections anywhere. His CD Antarctica (1998) of emperor penguins, weddell seals and their pups, wind and glaciers, is a landmark recording that captures life on the ice with startling depth and transparency. I asked Quin about the challenges that confronted him while recording in Antarctica.

Every opportunity that I have to work in the field presents its own unique set of difficulties and challenges, whether I am recording in a tropical, polar or temperate habitat. In the continuum of considerations that includes weather - with temperature, precipitation and humidity - terrain, accessibility, field support and other variables, I always find that there is a process of reconciling research and anticipation with actual immersion in any given environment. I never take anything for granted and am circumspect with regard to level of difficulty. I always begin my endeavours with an attitude that nothing will ever be as simple as I might, at first, expect it will be. With that said, some of the most demanding fieldwork that I have undertaken has been in polar regions - Antarctica, Greenland and Alaska.

Fieldwork in Antarctica presents very particular challenges and logistical considerations. Most obviously, working outside in freezing temperatures - often well below 0 degrees Fahrenheit and compounded by significant wind, with sudden, unpredictable changes in weather, can not only make for difficult recording conditions but can be fatal if you are ill-prepared and not careful. When heading out to record, I pack not only the recording equipment but also survival gear, and make sure that I have a plan mapped out for where I am going and when I plan to return - and a back-up plan in case the weather changes and I can't make it back to camp. It is not uncommon to leave with the sun shining and a slight breeze only to have weather close in, with visibility reduced to the point where you cannot see your hand extended in front of you, 
the temperature drop precipitously, and wind pick-up delivering the sting of ice and snow in your face. Hurricane blizzards, or 'Herbies' as they are called, with winds over $100 \mathrm{mph}$ can come out of nowhere. Since you always travel with at least one other person, you have to make sure you are both on the same page and have talked through details and gear before you leave. ${ }^{10}$

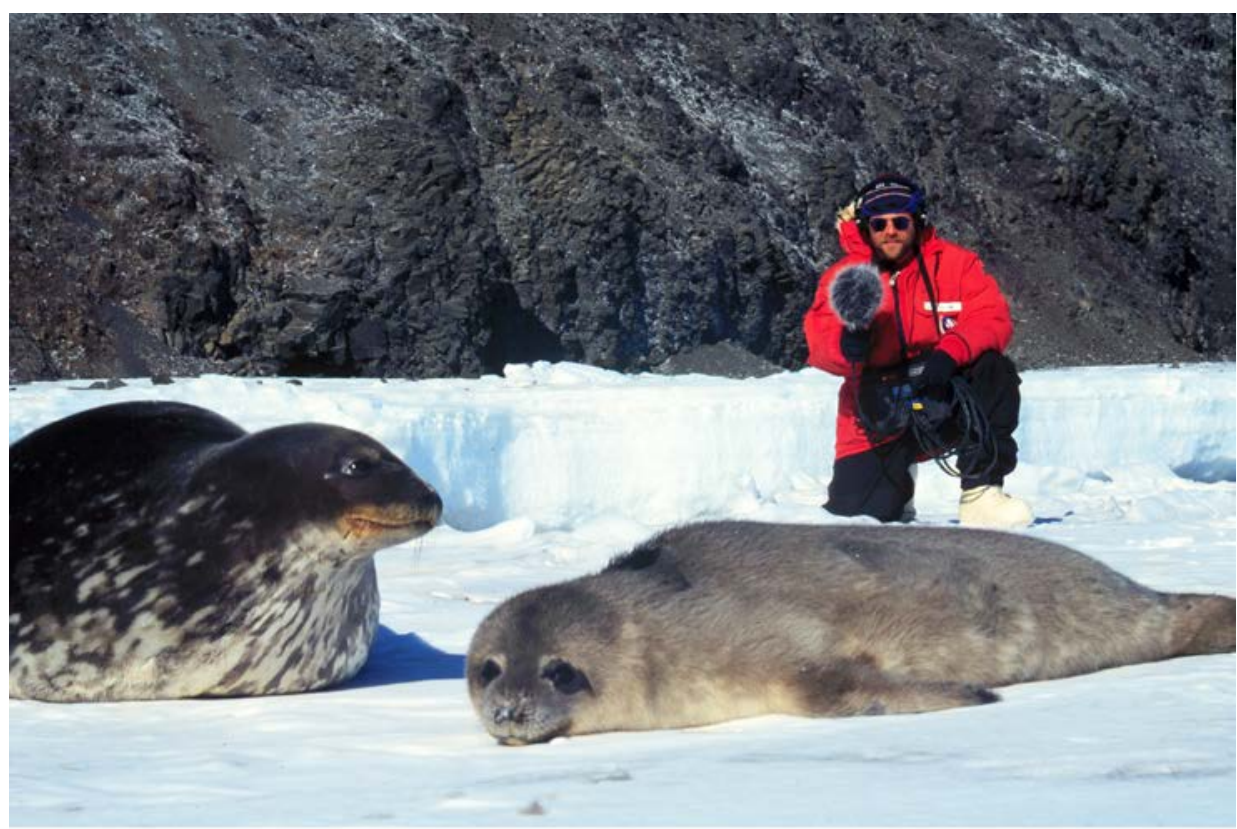

Douglas Quin Recording Weddell Seals in Antarctica. Photograph @ 1996 James H. Barker.

\section{Figure 2. Douglas Quin in Antarctica.}

Source: Image courtesy of the artist.

With hazards such as blizzards, hypothermia and frostbite to overcome, why would anyone want to subject themselves to this amount of hardship? It seems that there are other motives at play here than just the documentation of place. Overcoming physical and mental obstacles appears to be an important part of the creative process in which adversity heightens an artist's responsiveness to the environment.

Challenging myself both physically and intellectually is both its own reward and a way to be more deeply engaged with the process and subject of recording — be it recording an ambience or a specific species that I am trying to understand. I am not interested in purely exploring thrill seeking or 'extreme recording' as a type of solipsistic sport. Rather,

10 D Quin, pers. comm., 20 May 2009. 
when I push myself in this way, I find that I gain a fuller understanding of and appreciation for what it is I am listening to. In this, listening is not simply an auditory function but something that embraces different and complementary modalities of knowing and different senses. The physicality is a reminder of where you are and what you are feeling and sensing - beyond the 'mediated' experience of your recorder and microphones. In this, there is an aspect of empathetic identification in the process of field recording which, for me, is a dimension of practice. It is not just about mastering the gear, but of doing thorough research prior to heading off and then being open to all that you may not have anticipated in the moment of listening and recording. Furthermore, each experience, whether you succeed or fail, builds a cumulative base knowledge that makes every future recording attempt richer and fuller. ${ }^{11}$

As Quin points out, field recording sometimes requires an element of spontaneity and improvisation in order for the recordist to successfully adapt to the conditions of a location. This can yield surprising results, in which fleeting and ephemeral sounds appear and vanish in front of the microphone. Prior knowledge of a location, however, often assists in capturing these impromptu moments, as each environment is determined by a recurring set of acoustic and spatial dynamics that modulate throughout the day or season. To achieve a worthwhile outcome the recordist must consider many questions related to microphone selection, the proximity between microphone and sound event, the type of acoustics that inform the site, what other sounds occur in the location, the best time of day to record the sound, and how the sound changes over the course of the day. Observing these dynamics over a period of time enables the recordist to apply a more rigorous recording method to reveal the nuances comprising a location that are often hidden among an omnidirectional din.

\section{Crush grind}

Like Quin, Melbourne-based sound artist Geoff Robinson also cites the cold as providing the biggest challenge in working in the field.

I can remember several locations that I have recorded in that have all proved challenging due to one common factor, the cold. Three particular locations include recording in thigh-deep snow on the edge of a frozen lake outside of Saranac Lake in the Adirondack Mountains, New York State, and two locations in Iceland, Gullfoss and Jökulsarlon, one a waterfall and the other a lagoon at the edge of the Breiðamerkurjökull Glacier. 
I am interested in the sonic potential of natural environments in flux, particularly environments that have a degree of immediate movement, through either their surrounding weather or the geomorphology of the land. Inevitably I find myself going to cold environments where dramatic shifts happen to the landscape primarily due to low temperatures, freezing water and the consequential phenomena and forms that evolve from this such as snow, ice, glaciers, etc.

All three locations involved long periods of time standing still in snow surrounded by strong cold winds. Particularly the experiences I had in the Adirondacks were challenging and also, coming from Australia, my first real experience of a cold climate. While I was prepared to some degree and dressed appropriately (thermals, waterproof snow jacket, waterproof snow boots, etc.) standing still for 10-15 minute periods recording made me realise that my body was not coping. Feeling rather numb, rigid and shaking, I remained this way for several hours even with the car heater on to full. Quite a strange sensation, considering I am so used to the temperature of the immediate environment reacclimatising your body straight away. In Iceland I learnt from these experiences and worked out ways to move while recording (toes, fingers, legs, etc.) and to set up the microphone independently so I could keep moving (sometimes this is not possible if the sound source is moving). ${ }^{12}$

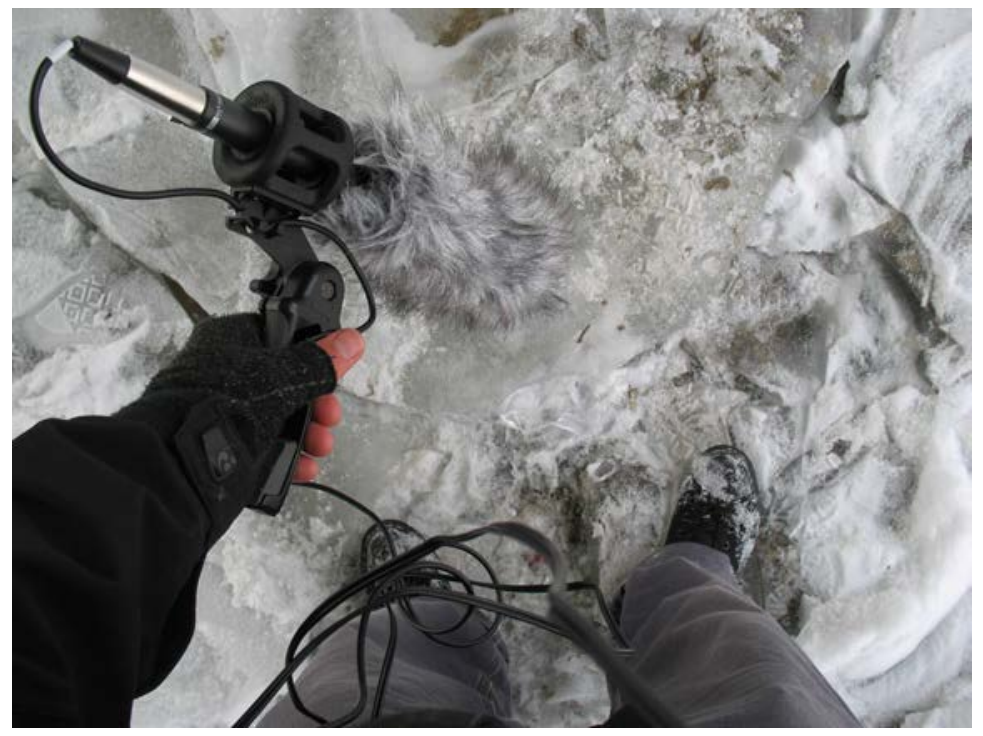

Figure 3. Geoff Robinson in Iceland.

Source: Image courtesy of the artist.

12 G Robinson, pers. comm., 17 May 2009. 


\section{The burden of dreams}

The physical and mental challenges that sound artists such as Quin and Robinson have had to overcome are significant, but what about the impact on the equipment used to capture these extraordinary locations? All technology is bound by a set of operational limits that determine the optimum conditions for it to function in a correct and reliable manner. What then are the effects of these punishing environments on the technology so critical to the field recordist? Melbourne sound artist Camilla Hannan describes the challenges of recording in the Amazon.

I spent two weeks on a sound art residency program at Mamori Lake in the Amazonas region of Brazil, hosted by Mamori Art Lab and conducted by Francisco Lopez. We spent two weeks going out twice a day into the jungle to do field recordings. The heat and humidity was quite intense as were the insects. Having lived in Queensland, I was not a stranger to these conditions, but Mamori was in a league of its own. Besides the personal comfort factor, the humidity adversely affected the microphones, in particular, condenser microphones. Microphones affected by moisture generate hum. The only way to remedy this is by drying the diaphragm in a moisture-free climate-controlled environment. This wasn't an option at Mamori where there was no air conditioning, let alone facilities for a climate-controlled room. Preventative measures such as using sealed waterproof bags and desiccant crystal sachets helped somewhat. Aside from problems with humidity there were constant power outages that meant a heavy reliance on battery power. ${ }^{13}$

English sound artist and instrument builder Max Eastley encountered a different set of problems recording in subzero temperatures on Spitsbergen, the largest island of the Svalbard archipelago in the Arctic Ocean.

Standard batteries will not work well in those environments so a lead acid battery is better as it can be topped up at any time, but they are heavy. Weight is crucial when you don't know how far you will have to walk over difficult terrain. Also leads can snap when the temperature is -30 Celsius, and the lubricants on a DAT recorder can freeze up, even at one or two degrees below zero. Spitsbergen has a particular problem for recording in that it is against the law to leave a settlement without being armed, as polar bears are a real danger. I had never been in an environment like that; I had to be accompanied at all times with one of the crew with a gun. ${ }^{14}$

13 C Hannan, pers. comm., 11 May 2009.

14 M Eastley, pers. comm., 14 May 2009. 
Aside from technical issues I wondered how working in a volatile region such as the Arctic affected the perception and awareness of the surrounding environment.

It changed the way I looked at the world. Human senses are dulled in urban environments, but in a remote place I found that seeing and hearing are essential to survival. Your perception is sharpened and you begin to listen and look for details in the environment. With those experiences of recording I realised how easily a series of unforeseen events could combine into a situation where you need all your resources. ${ }^{15}$

\section{Oblique strategies}

Can the artefacts generated by field recording in extremis simply function experientially to provide new knowledge of the natural world, or do they demand further questioning in order to understand an artist's intent, and therefore to measure the significance of their achievement? Of course a recording can do both, but unlike a musical composition, field recording opens itself up to interrogation, as the captured sounds and spaces are a window to the recordist's personal preoccupations, memories and subjective perceptions. Equally, field recording seems to carry with it a responsibility to educate and/ or raise awareness, both individual and collective, about the importance of our often overlooked auditory environment. I certainly believe that sound artists such as Quin and Watson have provided unique insights into the natural world that reflect a sensitive engagement between artist and location. A different philosophical outlook that draws on a broader interest in sound, perception and space though guides Hannan, which I believe highlights the manner in which many sound artists are now engaging with field recording.

Being isolated in the Amazon, away from the distractions of modern life meant I spent time thinking about how we listen and how the sonic landscape is made up. I thought a lot about the way sound is naturally spatialised, particularly in regard to depth of perception. I thought about the nature of silence, particularly within such a raucous environment. I thought about how the nature of recording changes the elements of a sound. I also considered notions of authenticity. To document an environment is not particularly important to me. What I am more interested in is how 'real' sounds can become abstractions of 
place and time. And following on from this and using ideas expounded by Francisco Lopez, how these recordings act as 'absolute sounds' devoid of reference or frameworks. ${ }^{16}$

\section{Concluding remarks}

The adaptation of numerous theoretical and philosophical references from acoustic ecology, soundscape composition, bioacoustics and phonography has enabled sound artists to forge new concepts and strategies to document both the natural and built environment, using increasingly portable and discreet recording equipment. Their interest and determination to access remote locations will undoubtedly continue to grow as both technology and travel become cheaper. I will be listening with great interest as new frontiers are revealed, to see how well I can spot the difference between the familiar and the strange. 
This text is taken from Antarctica: Music, sounds and cultural connections, edited by Bernadette Hince, Rupert Summerson and Arnan Wiesel, published 2015 by ANU Press, The Australian National University, Canberra, Australia. 